\title{
MULTIFUNCIONALIDADE DA AGRICULTURA FAMILIAR E SEGURANÇA ALIMENTAR: CAMINHOS PARA A CONCRETIZAÇÃO DOS DIREITOS HUMANOS AGROALIMENTARES
}

\section{MULTIFUNCTIONALITY OF FAMILY FARMING AND FOOD SECURITY: PATHS FOR THE CONCRETION OF AGRIFOOD HUMAN RIGHTS}

Gil Ramos de Carvalho Neto ${ }^{1}$

\section{RESUMO}

A agricultura familiar tem um importante papel social, econômico e ambiental. Sua multifuncionalidade vem ao encontro da possibilidade de efetivação dos direitos humanos agroalimentares. O conceito legal brasileiro de segurança alimentar reforça a necessidade de respeito a esses direitos, sendo que a opção política pela agricultura familiar pode consagrar a sociedade como a maior beneficiada com a garantia de cumprimento dos requisitos para uma alimentação segura.

Palavras-chave: agricultura familiar; segurança alimentar; multifuncionalidade; direitos humanos agroalimentares.

\begin{abstract}
Family farming has an important social, economic and environmental role. Its multifunctionality meets the possibility of concretion of agrifood human rights. The Brazilian legal concept of food security highlights the need to respect these rights, and family agriculture by policy option can enshrining that society as the greatest benefit from the guarantee of fullfillment of the requirements for safe feeding.
\end{abstract}

Keywords: Family farming; food security; multifunctionality; agrifood human rights.

\footnotetext{
${ }^{1}$ Bacharel em Direito, Universidade Estadual Paulista - UNESP, (Brasil). Especialista em Direito Ambiental pela Universidade Federal do Paraná , UFPR, Paraná, (Brasil). E-mail: gilrcneto@ yahoo.com.br
} 


\section{INTRODUÇÃO}

O presente artigo tem como objeto estudar a segurança alimentar propiciada pela agricultura familiar, quanto a seu aspecto de multifuncionalidade, de forma a efetivar os direitos humanos agroalimentares. Objetiva-se mostrar que a opção política pela agricultura familiar é adequada e necessária para que haja efetiva segurança alimentar no Brasil e sejam atendidos os direitos humanos afetos à questão.

Utilizou-se na pesquisa o método indutivo. Foram trazidos os conceitos de agricultura familiar e de segurança alimentar e, a partir deles, apresentou-se a multifuncionalidade da agricultura familiar. Após, relacionou-se a mesma com os direitos humanos agroalimentares, de forma a verificar se os mesmos são atingidos caso se faça opção por essa modalidade de produção alimentar.

De forma a atingir os fins esperados, o artigo será dividido em tópicos. No primeiro deles, apresentar-se-á de forma sucinta o que é agricultura familiar.

No segundo, apresentar-se-á o conceito de segurança alimentar, com uma contextualização histórica e os desdobramentos no Brasil. No terceiro tópico, serão feitos apontamentos no tocante à multifuncionalidade da agricultura familiar, de forma a traçar um liame entre os temas já apresentados anteriormente.

No quarto tópico, apresentar-se-ão os direitos humanos agroalimentares que estão mais diretamente ligados à questão ora estudada - o direito humano à alimentação e o direito ao meio ambiente. Por fim, serão apresentadas as conclusões do estudo, relacionando os temas trabalhados no decorrer deste artigo.

\section{AGRICULTURA FAMILIAR}

Apesar de não ter sido a primeira modalidade de organização produtiva, já que durante a primeira revolução agrícola, do neolítico, os arranjos produtivos coletivos foram pioneiros, estima-se que há cerca de $10 \mathrm{mil}$ anos, mediante incessantes mudanças técnicas e organizacionais, a agricultura familiar começou a se fazer presente na história das civilizações (BAIARDI; ALENCAR, 2014). 
A existência da agricultura familiar evidencia a relevância do conceito de segurança alimentar, em especial para o Brasil, país expoente no agronegócio global.

Sua própria nomenclatura já demonstra uma diferença estrutural do empreendimento: trata-se de uma unidade produtiva na qual atua pequena quantidade de pessoas, com fortes vínculos afetivos entre si, o que lhe dá uma característica mais identitária do que propriamente negocial, embora esta última também exista e seja muito importante para o propósito da segurança alimentar. Trata-se de um pequeno negócio, de estabilidade maior do que a de outros tipos de estabelecimentos familiares, com menor vulnerabilidade a conjunturas e a ciclos de crescimento e de extinção (BAIARDI; ALENCAR, 2014).

A FAO reconhece que, tanto em países desenvolvidos quanto em países em desenvolvimento, a agricultura familiar é a forma predominante de agricultura no setor de produção de alimentos e tem um importante papel socioeconômico, ambiental e cultural (FAO, 2014, online).

Quanto ao seu escopo, a agricultura familiar inclui todas as atividades agrícolas de base familiar e está ligada a diversas áreas do desenvolvimento rural. Ela consiste em um meio de organização das produções agrícola, florestal, pesqueira, pastoril e aquícola que são gerenciadas e operadas por uma família e predominantemente dependente de mão de obra familiar, tanto de mulheres quanto de homens (FAO, 2014, online).

No âmbito jurídico brasileiro, o art. $3^{\circ}$ da Lei $n^{\circ} 11.326 / 2006$ - Lei da Política Nacional de Agricultura Familiar - apresenta uma definição técnica de agricultor familiar para o agricultor que pratica atividades no meio rural, atendendo, simultaneamente, a uma combinação de critérios: limite de área, utilização predominantemente de mão de obra da própria família nas atividades econômicas, percentual mínimo da renda familiar originada no próprio estabelecimento e direção da unidade produtiva pela própria família (BRASIL, 2006, online).

A definição jurídica pátria de pequena propriedade familiar, por sua vez, se encontra positivada no art. $3^{\circ}$, inciso V, da Lei ${ }^{\circ}$ 12.651/2012 - Código Florestal Brasileiro - tratandose da propriedade "[...] explorada mediante o trabalho pessoal do agricultor familiar e empreendedor familiar rural, incluindo os assentamentos e projetos de reforma agrária, e que atenda ao disposto no referido art. $3^{\circ}$ da Lei $n^{\circ} 11.326$, de 24 de julho de 2006." (BRASIL, 2012, online).

A relevância da agricultura familiar para a população brasileira é imensa, embora a divulgação de tal fato não seja a ideal. Segundo dados do Censo Agropecuário de 2006 (online), 
a agricultura familiar constitui a base econômica de $90 \%$ dos municípios brasileiros com até 20 mil habitantes; responde por $35 \%$ do produto interno bruto nacional; e absorve $40 \%$ da população economicamente ativa do país (IBGE, online).

Dados do mesmo o Censo quanto à produção agrícola indicam que a agricultura familiar produz $87 \%$ da mandioca, $70 \%$ do feijão, $46 \%$ do milho, $38 \%$ do café, $34 \%$ do arroz e $21 \%$ do trigo do Brasil. Por sua vez, quanto à pecuária, ela é responsável por $60 \%$ da produção de leite, além de 59\% do rebanho suíno, 50\% das aves e 30\% dos bovinos do país (IBGE, online).

Percebe-se assim que a agricultura familiar possui enorme importância econômica por estar vinculada ao abastecimento do mercado interno nacional e também ao controle da inflação dos alimentos consumidos pelos brasileiros.

\section{SEGURANÇA ALIMENTAR}

\subsection{Histórico}

O conceito de segurança alimentar é aceito em todo o planeta. Porém, sua definição tem que levar em conta a realidade fática de casa país que será objeto de suas políticas alimentares.

A elaboração conceitual de segurança alimentar remonta ao período pós-Primeira Guerra Mundial. À época, essa ideia estava ligada a aspectos de segurança nacional e à capacidade de cada país alimentar seu próprio povo. Tal cenário estava ligado à assistência alimentar, com uso de excedentes de alimentos, voltando-se para o âmbito de política de estocagem estratégica de gêneros alimentares.

Houve a natural constatação de divergências nas legislações nacionais quanto à matéria alimentar, a partir do crescimento do comércio internacional de alimentos. A essa constatação somou-se a preocupação com o uso crescente de substâncias químicas na indústria alimentar. Dessa forma, o cenário desencadeou as primeiras reuniões conjuntas da Organização para a Alimentação e Agricultura (FAO) e a Organização Mundial da Saúde, ambas afetas à ONU, em 1950 (WOLFF, 2015). A segurança alimentar agregou, então, um enfoque sanitário.

Após um período de escassez de gêneros alimentares ocorrida nos anos 1970, passouse a entender a segurança alimentar como sendo uma questão ligada à produção de alimentos e não do direito a eles - uma visão produtivista e neomalthusiana (VALENTE, 2002).

A partir de então, a noção de segurança alimentar posteriormente passa a não se limitar meramente à questão do abastecimento alimentar e nem mesmo à questão sanitária dos 
alimentos. A FAO assumiu a preponderância na promoção dos debates referentes ao tema da alimentação em nível internacional e, em razão disso, promoveu diversas conferências sobre o tema. Todas elas vieram a contribuir, sequencialmente, para uma compreensão mais abrangente e mais apropriada de segurança alimentar.

Um desses eventos em particular, a Conferência Mundial sobre a Alimentação de 1974, foi muito significativo no que tange ao reconhecimento do problema da fome, em especial nos países em desenvolvimento, como o resultado de circunstâncias históricas. O fato de esses países terem sido marcados por serem submetidos ao domínio estrangeiro e colonial impediu a sua plena emancipação e, consequentemente, o seu progresso. Quanto a isso, Elisabete Maniglia (2009) menciona que

O enfoque estava no alimento e não no ser humano. Com o aumento na produção de alimentos, nos fins da década de 1970, o mundo despertou para a realidade e passou a encarar a situação da fome e desnutrição como um problema realmente de acesso e não de produção.

Os anos 1980, por sua vez, assistem à constatação de que a fome e a desnutrição são causados mais por problemas ligados ao acesso aos alimentos do que à produção dos mesmos. Quanto à evolução do conceito de segurança alimentar há avanços, pois o mesmo passou a incluir questões como a oferta estável de alimentos e de garantia de acesso a eles, bem como de sua qualidade. Independentemente disso, o combate à miséria se fazia necessário para que se garantisse a segurança alimentar. Nesse sentido, Elisabete Maniglia (2009) afirma que

O Banco Mundial, em 1986, definiu segurança alimentar como "o acesso por parte de todos, todo o tempo, a quantidades suficientes de alimentos para levar uma vida ativa e saudável". Nesse ínterim, passa-se a visão de que alimentos na mesa significam poder aquisitivo e não autossuficiência na produção. Poder aquisitivo representa crescimento econômico, distribuição de renda e redução da pobreza.

Na década de 1990, o conceito de segurança alimentar passa a incluir questões afetas à qualidade nutricional, biológica, sanitária e nutricional dos alimentos. Além delas, outras questões como equidade, justiça e ética, bem como a sustentabilidade, passam a influir na estruturação do conceito já mencionado.

\subsection{Construção do conceito no Brasil}


Os reflexos da Revolução Verde no Brasil, relevantes para a definição do conceito de segurança alimentar, se fazem evidentes com a elaboração dos Planos de Desenvolvimento da década de 1970. Eles orientaram o país para a produção agrícola baseada na monocultura de exportação e com uso de insumos tecnológicos, de forma a permitir o lucro fácil em detrimento dos interesses da sociedade brasileira. Como consequência, vieram diversas lutas sociais que frutificaram a partir dessa opção de desenvolvimento nacional. A pressão exercida sobre os governantes da época quanto à fome e à miséria foi grande e deu resultado: o termo "segurança alimentar" é citado pela primeira vez, em 1985, em documento do Ministério da Agricultura intitulado "Segurança Alimentar: proposta de uma política de combate à fome".

No tocante à situação da segurança alimentar em âmbito internacional, percebe-se que o objetivo brasileiro era o mesmo: atender as necessidades alimentares da população e atingir a autossuficiência nacional na produção de alimentos (GRASSI NETO, 2013).

Apesar da conquista, a luta dos movimentos sociais não arrefeceu e se somou a iniciativas civis, como a criação da Ação pela Cidadania, contra a Fome, a Miséria e pela Vida, na década de 1990, pelo sociólogo Herbert de Souza. As lutas conjuntas tornam as ações assistenciais da sociedade civil como um avanço, ainda que tímido, na luta contra a fome. Algumas ações do governo Itamar Franco vieram a ser decisivas para a implementação de uma política nacional de segurança alimentar, como o mapeamento da fome no país realizado pelo Instituto de Pesquisa Econômica Aplicada (IPEA) e a criação do Conselho Nacional de Segurança Alimentar (CONSEA).

Dois importantes avanços estão ligados à criação do CONSEA: o combate à fome e à miséria passam a ser vistos como um problema de governo e uma questão estratégica, ficando sua coordenação diretamente vinculada ao gabinete do Presidente da República; e inicia-se um trabalho de coordenação das ações governamentais de forma intersetorial, entre os diferentes níveis de governo e sociedade civil no sentido de reduzir duplicidades, superposições e de atingir os objetivos propostos. Logo, entende-se que foi o CONSEA que conseguiu incluir, de forma efetiva, a segurança alimentar na agenda política brasileira (VALENTE, 2002a).

Embora tenha conseguido obter diversas conquistas em seu âmbito de atuação, o CONSEA foi extinto no governo Fernando Henrique Cardoso e substituído pelo Conselho da Comunidade Solidária. O problema foi que o substituto não manteve o foco na questão alimentar, além de elaborar estratégias de desenvolvimento social que ficaram no campo meramente teórico. 
A extinção do CONSEA fundamentou-se na contradição básica entre a proposta do governo de Fernando Henrique Cardoso e do próprio conselho: o primeiro priorizava a estabilização da economia brasileira a partir da sua inserção sem critério definido na economia globalizada, enquanto que o segundo visava o enfrentamento das condições precárias de vida de uma grande maioria da população brasileira (VALENTE, 2002a).

A retomada efetiva da luta contra a fome e pela segurança alimentar na agenda política brasileira ocorreu no governo de Luís Inácio Lula da Silva, com a criação do Programa Fome Zero e a recriação do CONSEA. A retomada e continuidade dos eventos e debates sobre o tema levou à construção de um conceito de conceito de segurança alimentar brasileiro que veio a ser promulgado em 2006, pela Lei Orgânica de Segurança Alimentar e Nutricional (LOSAN), em seu artigo $3^{\circ}$, a saber:

A segurança alimentar e nutricional consiste na realização do direito de todos ao acesso regular e permanente a alimentos de qualidade, em quantidade suficiente, sem comprometer o acesso a outras necessidades essenciais, tendo como base práticas alimentares promotoras de saúde que respeitem a diversidade cultural e que sejam ambiental, cultural, econômica e socialmente sustentáveis (BRASIL, 2006).

Em seu bojo, a LOSAN afirma que a alimentação adequada é um direito fundamental do homem, inerente à dignidade da pessoa humana e indispensável à realização dos direitos constitucionais. Assim, o Poder Público deve adotar as políticas e ações necessárias para promover e garantir a segurança alimentar e nutricional da população em caráter permanente, mesmo considerando possíveis mudanças políticas a nível governamental.

A segurança alimentar e nutricional (SAN) passa a se constituir na materialização de um direito que postula o acesso regular e permanente a alimentos de qualidade e em quantidade suficiente, sendo que sua promoção não deve comprometer a satisfação de outras necessidades essenciais à vida humana. Importante também é frisar que falar em promoção da SAN é falar em promoção da saúde, em respeito à diversidade cultural e em sustentabilidade econômica e ambiental (MALUF; REIS, 2013).

A partir da promulgação da lei, a segurança alimentar e nutricional converteu-se em objetivo público, estratégico e permanente, características que a colocaram entre as categorias nucleares para a formulação das políticas de desenvolvimento de um país (MALUF, 2007). 


\subsection{Abrangência conceitual}

De acordo com o art. $4^{\circ}$ da LOSAN, a abrangência da segurança alimentar e nutricional inclui:

I - a ampliação das condições de acesso aos alimentos por meio da produção, em especial da agricultura tradicional e familiar, do processamento, da industrialização, da comercialização, incluindo-se os acordos internacionais, do abastecimento e da distribuição dos alimentos, incluindo-se a água, bem como da geração de emprego e da redistribuição da renda;

II - a conservação da biodiversidade e a utilização sustentável dos recursos;

III - a promoção da saúde, da nutrição e da alimentação da população, incluindo-se grupos populacionais específicos e populações em situação de vulnerabilidade social;

IV - a garantia da qualidade biológica, sanitária, nutricional e tecnológica dos alimentos, bem como seu aproveitamento, estimulando práticas alimentares e estilos de vida saudáveis que respeitem a diversidade étnica e racial e cultural da população;

$\mathrm{V}$ - a produção de conhecimento e o acesso à informação; e

VI - a implementação de políticas públicas e estratégias sustentáveis e participativas de produção, comercialização e consumo de alimentos, respeitando-se as múltiplas características culturais do País (BRASIL, 2006).

Percebe-se aqui que a expressão "segurança alimentar e nutricional" (SAN) engloba desde a promoção propriamente dita do acesso aos alimentos até os modos de produção, armazenamento, processamento e comercialização dos mesmos, sendo que eles devem estar em condições de qualidade suficientes.

A proteção ambiental também deve se fazer presente para que se possa falar em SAN, bem como a promoção da saúde de toda a população. A falta de sustentabilidade dos modos pelos quais os bens alimentares são produzidos pode contribuir para a falta de segurança alimentar.

Até mesmo a falta de acesso aos alimentos que sejam produzidos de forma sustentável e com qualidade pode afetar a SAN. Santos (2012) expõe que de nada adiantará promover práticas que garantam a existência de alimento para a população se, ao final, o preço de tais alimentos for tão alto que, para a pessoa que os adquira, não sobre dinheiro para mais nada. Assim, a oferta de gêneros alimentares é importante, mas seus preços devem ser justos e acessíveis, para que não comprometam o acesso dos indivíduos aos seus demais direitos essenciais.

Relevante mencionar que a lei abre até mesmo a possibilidade de cooperação internacional para o atendimento a esse importante direito humano fundamental. Nos termos 
do artigo $6^{\circ}$ da LOSAN, “o Estado brasileiro deve empenhar-se na promoção de cooperação técnica com países estrangeiros, contribuindo assim para a realização do direito humano à alimentação adequada no plano internacional” (BRASIL, 2006a).

Observa-se que a qualidade do texto da LOSAN é tamanha que ela vem sendo apresentada como um modelo de legislação aos Estados-partes do MERCOSUL, que ainda vem trabalhando para a promoção de programas de segurança alimentar e nutricional em benefício das populações dos Estados-partes do MERCOSUL e Estados Associados (GRASSI NETO, 2013).

\section{MULTIFUNCIONALIDADE DA AGRICULTURA FAMILIAR}

A agricultura familiar tem um importante papel multifuncional, já reconhecido desde a Conferência Rio-92, notadamente quanto à segurança alimentar e o desenvolvimento sustentável.

A implantação do conceito de multifuncionalidade é o reconhecimento explícito que a agricultura não é somente responsável pela produção de alimentos, mas também pela conservação dos valores culturais, históricos, ambientais e paisagísticos próprios do mundo rural (TRENTINI, 2002, p. 4). Há estudos na área de ciências sociais que identificam pelo menos quatro expressões da multifuncionalidade da agricultura familiar, a saber: a reprodução socioeconômica das famílias rurais; a promoção da segurança alimentar das famílias rurais e da sociedade; a manutenção do tecido social e cultural; e a preservação dos recursos naturais e da paisagem rural (CARNEIRO; MALUF, 2003).

Existe o reconhecimento em face da agricultura familiar quanto a esta ser uma forma de produção de alimentos que, além de assegurar a subsistência de um determinado grupo, não visa apenas ao lucro e ao crescimento econômico irracional, mas ao desenvolvimento sustentável do meio rural.

Em consentâneo com esse mesmo desenvolvimento sustentável, a agricultura familiar é marcada pela solidariedade entre os agricultores, que interagem de forma colaborativa, promovendo a troca de experiências e de produtos, permuta de sementes e fomento do mercado interno. Toda essa cadeia de interações demonstra a existência do trabalho de muitos lavradores.

O modelo da agricultura familiar pode, por sua própria formatação, desenvolver-se em pequenas áreas, sem prejuízo à diversificação agrícola e incluindo sustentabilidade em cada 
uma de suas ações. Essa postura efetiva a função social da propriedade rural e traz como consequência a possibilidade de permanência do homem no campo.

Vale ressaltar que o desenvolvimento da agricultura familiar não depende apenas das suas condições de produção agroecológica e das características territoriais do país onde a mesma ocorre, mas também de um ambiente político e de acesso à terra, à tecnologia de produção, ao financiamento e aos mercados consumidores, entre outros.

Nesse sentido, verifica-se que as principais políticas multifuncionais governamentais têm como objetivo o estímulo à agricultura familiar como forma de garantir o mínimo necessário para a alimentação das famílias que vivem na zona rural. Políticas de incremento da renda, sejam por transferências governamentais, sejam por incentivo à produção, acabam por viabilizar a permanência do homem no campo (SANTOS; COUTO; ROCHA, online).

As políticas governamentais em geral pretendem transferir renda para as famílias por intermédio de programas socais, como é o caso do Bolsa-Família. Porém, não há quaisquer programas de estímulo à demanda por produtos social e ecologicamente sustentáveis. Programas que venham a estimular essas demandas poderiam gerar, através do mercado, uma maior sustentabilidade econômica tanto para o governo quanto para os produtores familiares, que passariam a ser remunerados pela sociedade haja vista o caráter multifuncional da sua atividade agrícola (SANTOS; COUTO; ROCHA, online).

No primeiro momento, as políticas de transferência de renda são fundamentais, pois garantem o mínimo necessário para a sobrevivência e reprodução das famílias. Todavia, em um segundo momento, o papel das políticas públicas passa a ser o de fomentar a organização dos produtores e viabilizar a comercialização da sua produção, atuando como divulgador e certificador dos produtos originários das unidades familiares. Esse tipo de desenvolvimento rural torna-se sustentável a partir da inserção dos produtores familiares em um novo mercado, estimulado pelo Estado (SANTOS; COUTO; ROCHA, online). Isso vem a contribuir para a segurança alimentar no contexto de efetivação da produção agrícola de modelo familiar.

Percebe-se assim que a realização da multifuncionalidade da agricultura familiar está vinculada a uma conjuntura propícia, que confira a este modelo de produção agrícola o seu real significado. Além disso, valores socialmente positivos como tradição, desenvolvimento, eficiência econômica e proteção da natureza devem se fazer presentes.

\section{DIREITOS HUMANOS AGROALIMENTARES}


Quanto a alguns dos aspectos mais diretamente relacionáveis ao conceito de segurança alimentar, os principais direitos humanos que estão ligados a ela seriam: o direito à alimentação, de forma mais evidente, e também o direito ao meio ambiente, em decorrência do conceito legal da seguridade alimentar.

Com influência dos diplomas internacionais já mencionados acima, além da Declaração de Direitos Humanos de Viena (1993), percebe-se que o direito à alimentação está previsto em diversos instrumentos na ordem jurídica internacional. Ele faz parte do direito mais amplo a um padrão de vida adequado (EIDE, 2002). Quanto à internalização desse direito nos países latinos, Dirceu Pereira Siqueira explica que os tópicos previstos na normativa internacional sobre a temática acabam por se repetir na tradição constitucional ibero-americana (SIQUEIRA, 2015). Ainda assim, a partir dos Pactos de 1966, passa a existir o reconhecimento do direito à alimentação como direito humano básico. Iniciou-se então a trajetória da busca pela garantia de alimentação a toda a humanidade.

De acordo com a Declaração Universal dos Direitos Humanos, a alimentação é um meio necessário para a garantia da dignidade da pessoa humana. Para isso, faz-se necessária a chamada alimentação adequada, com a finalidade de se alcançar o bem-estar nutricional. A alimentação é um direito de cada cidadão e nenhum fator, de qualquer ordem que seja, justifica a negação do acesso à alimentação adequada a um ser humano (VALENTE, 2002).

Segundo Vanesca Freitas Bispo (2014), o direito à alimentação, aliado a outros, é considerado um instrumento capaz de dar ao ser humano um padrão de vida digno e de bem estar. Isso a torna um item do rol de obrigações estatais e não mero auxílio social.

O conceito de alimentação pressupõe ações em um caráter muito mais amplo do que apenas o seu aspecto qualitativo ou quantitativo, requerendo políticas que tenham essencialmente um caráter estrutural. Objetivam o desenvolvimento gradativo e contínuo de todos os fatores que direta ou indiretamente afetam tal direito, o que implica no respeito a todas as dimensões previstas na lei de segurança alimentar e nutricional, além de outras que se relacionem ao direito humano à alimentação adequada (BISPO, 2014).

O direito à alimentação adequada é o direito mais básico do homem, vinculando-se diretamente ao próprio direito à vida - pois sem alimento não há como se ter vida e, consequentemente, os demais direitos dela decorrentes. Para que essa vida seja uma vida digna, 
respeitando o princípio da dignidade da pessoa humana, o alimento deve ser acessível, seguro e em quantidade necessária para atender aos fins a que ele se destina.

Para que se possa atingir esse direito, o Estado brasileiro deverá, de acordo com o artigo 11, [2], do Pacto Internacional de Direitos Econômicos, Sociais e Culturais, adotar medidas para melhorar as práticas de produção, conservação e distribuição de alimentos, fazendo uso de todo o conhecimento técnico e científico disponível e pelo desenvolvimento ou reforma dos sistemas agrários (EIDE, 2002). Nota-se assim o mandamento implícito ao suporte que deve ser fornecido à agricultura familiar.

Além disso, deverão ser todas as medidas que se fizerem necessárias para garantir a segurança alimentar aos cidadãos sob jurisdição de determinado Estado, incluindo eventualmente programas sociais, redes de segurança e, se as medidas tomadas em isolado pelo próprio país não se fizerem suficientes, a busca por ajuda internacional. Eide (2002) afirma que o direito à alimentação só pode ser totalmente usufruído se estiver ligado à realização de todos os outros direitos humanos, inclusive.

A falta de alimentos em quantidades adequadas leva à insatisfação das sociedades que dele necessitam, o que pode violar mais um direito humano: o direito à paz. A fome pode levar à guerra e uma guerra pode trazer a fome. Esse seria um mal visível e retumbante da inadequação da alimentação.

Além disso, garantir a alimentação adequada passa por, necessariamente, preservar a natureza e as demais formas de vida para que a própria humanidade não seja prejudicada em algum dos seus direitos mais básicos. O direito humano ao meio ambiente vincula-se a esse propósito, sendo que a preocupação do homem com os aspectos ambientais do planeta data de um período próximo ao de sua preocupação jurídica alimentar.

O direito humano ao meio ambiente tem seu embasamento nos Pactos de 1966, já mencionados. Mas a proteção do meio ambiente se desenvolveu de modo diferente: surge com o reconhecimento de uma crise ambiental global. A positivação de normas de proteção ao meio ambiente se inicia com o Princípio I da Declaração de Estocolmo de 1972:

O homem tem o direito fundamental à liberdade, à igualdade e ao desfrute de condições de vida adequadas em um meio ambiente de qualidade tal que lhe permita levar uma vida digna e gozar de bem-estar, tendo a solene obrigação de proteger e melhorar o meio ambiente para as gerações presentes e futuras (BRASIL, 2016, online). 
A proteção ambiental é uma necessidade básica do homem, reconhecendo-se que o meio ambiente é indispensável. Embora legalmente os seres humanos valham muito mais do que o meio ambiente como objeto de proteção, o bem-estar do homem depende do bem-estar de todo os seres vivos.

A partir da Conferência de Estocolmo de 1972, as iniciativas para a proteção do direito ao meio ambiente aumentaram, se diversificaram e foram positivadas em diversas partes do planeta. No Brasil, diplomas como a Lei de Política Nacional do Meio Ambiente e a própria Constituição Federal de 1988 são exemplos de que a tutela ambiental foi estabelecida de maneira ampla e profunda.

Os direitos humanos e o direito ao meio ambiente estão interligados porque têm como objetivo a qualidade de vida no planeta. Essa preocupação extrapola o universo nacional e atinge o global, abrangendo os pactos e tratados internacionais, com importantes e fundamentais reflexos para cada uma das nações do planeta.

A própria globalização do mercado deveria ser regulamentada pela aplicação de padrões de meio ambiente e de direitos humanos universais pelos principais organismos internacionais, de forma que o comércio liberalizado seja refreado em prol dos direitos humanos mais básicos existentes.

Tal assertiva vem de encontro à irrevogabilidade e à imprescritibilidade do direito humano fundamental ao meio ambiente em sua roupagem dos dias atuais. Dessa maneira, Beuter (2006) explica que perceber e proteger o meio ambiente, em sua globalidade, se traduz em dimensioná-lo como o direito ao desenvolvimento humano num ambiente global, que necessita de esforços para a consagração do meio ambiente sadio que se encontra sob o domínio dos direitos humanos.

Vale lembrar que, para se alimentar, o homem depende de outras formas de vida. Assim, o direito humano à alimentação e o direito humano ao meio ambiente devem ser reconhecidos e respeitados em conjunto para que se possa vir a atingir a verdadeira segurança alimentar em benefício de toda a humanidade. 


\section{CONCLUSÕES}

A segurança alimentar, conceito construído ao longo de décadas no âmbito global, relaciona-se de maneira marcante com importantes direitos humanos fundamentais, especialmente o direito à alimentação e o direito ao meio ambiente. $\mathrm{O}$ aprimoramento conceitual no decorrer dos tempos foi impulsionado pelas mudanças sociais, políticas e econômicas no âmbito da produção agroalimentar e da necessária distribuição de seus bens pelo planeta, além do incremento da preocupação da humanidade com as questões ambientais e sociais.

A agricultura familiar, opção alternativa ao modelo dominante do agronegócio, tem características mais adequadas à essa nova realidade da humanidade. Sua produção parte de pequenas propriedades, com uso de mão de obra predominantemente familiar, nas quais as relações sociais e zelo pelo equilíbrio ambiental são intrínsecos ao próprio modelo produtivo. Assim, em se considerando o conceito legal brasileiro de segurança alimentar, constata-se que uma opção política pela agricultura familiar é adequada e necessária para que haja efetividade na segurança alimentar do país.

Quanto à multifuncionalidade da agricultura familiar, depreende-se que a mesma evidencia que uma vertente agrícola direcionada apenas para a produção agroalimentar desenfreada, sem preocupações com os desdobramentos econômicos, sociais e ambientais, vai na contra mão do amadurecimento da humanidade para os direitos humanos fundamentais. Será muito mais difícil que estes sejam atingidos em sua plenitude através do modelo tradicional de agricultura - monocultura, latifúndio, vendas prioritariamente voltadas à exportação, uso de insumos prejudiciais ao meio ambiente.

\section{REFERÊNCIAS}

BAIARDI, Amilcar; ALENCAR, Cristina Maria Macêdo de. Agricultura familiar, seu interesse acadêmico, sua lógica constitutiva e sua resiliência no Brasil. Rev. Econ. Sociol. Rural, Brasília, v. 52, supl. 1, p. 45-62, 2014 . Disponível em $<$ http://www.scielo.br/scielo.php?script=sci_arttext\&pid=S0103$20032014000600003 \& \operatorname{lng}=$ pt\&nrm=iso>. acessos em 24 set. 2016. http://dx.doi.org/10.1590/S0103-20032014000600003.

BEUTER, Carla Simone. Cidadania planetária: uma nova percepção socioambiental que contempla o meio ambiente como um direito humano fundamental. In: SPAREMBERGER, 
Raquel Fabiana Lopes; PAVIANI, Jayme (Orgs.). Direito ambiental: um olhar para a cidadania e sustentabilidade planetária. Caxias do Sul: Educs, 2006.

BISPO, Vanesca Freitas. Direito fundamental à alimentação adequada: a efetividade do direito pelo mínimo existencial e a reserva do possível. Curitiba: Juruá, 2014.

BRASIL. Lei n. 11.326, de 24 de julho de 2006. Estabelece as diretrizes para a formulação da Política Nacional da Agricultura Familiar e Empreendimentos Familiares Rurais. Diário Oficial da União, Brasília, DF, 25 jul. 2006. Disponível em: < http://www.planalto.gov.br/ccivil_03/_ato2004-2006/2006/lei/111326.htm>. Acesso em: set. 2016.

BRASIL. Lei n. 11.346, de 15 de setembro de 2006. Cria o Sistema Nacional de Segurança Alimentar e Nutricional - SISAN com vistas em assegurar o direito humano à alimentação adequada e dá outras providências. Diário Oficial da União, Brasília, DF, 18 set. 2006. Disponível em: <http://www.planalto.gov.br/ccivil_03/_ato2004-2006/2006/lei/111346.htm>. Acesso em: set. 2016.

Lei n. 12.651, de 25 de maio de 2012. Dispõe sobre a proteção da vegetação nativa; altera as Leis nos 6.938, de 31 de agosto de 1981, 9.393, de 19 de dezembro de 1996, e 11.428, de 22 de dezembro de 2006; revoga as Leis nos 4.771, de 15 de setembro de 1965, e 7.754, de 14 de abril de 1989, e a Medida Provisória no 2.166-67, de 24 de agosto de 2001; e dá outras providências. Diário Oficial da União, Brasília, DF, 28 mai. 2012. Disponível em: <http://www.planalto.gov.br/ccivil_03/_ato2011-2014/2012/lei/112651.htm>. Acesso em: set. 2016.

BRASIL. Ministério do Meio Ambiente. Declaração da Conferência das Nações Unidas para o Meio Ambiente Humano. Disponível em:

<www.mma.gov.br/estruturas/agenda21/_arquivos/estocolmo.doc>. Acesso em 27 ago. 2016.

CARNEIRO, Maria José; MALUF, Renato Sérgio Jamil. (Org.). Para além da produção: multifuncionalidade e agricultura familiar. Rio de Janeiro: Mauad, 2003.

EIDE, Asbjorn. A realização dos direitos econômicos, sociais e culturais - o direito à alimentação adequada e a estar livre da fome. In: VALENTE, Flávio Luiz Schieck (Org.). Direito humano à alimentação: desafios e conquistas. São Paulo: Cortez, 2002.

FAO. O que é agricultura familiar? Roma, 2014b. Disponível em: <http://www.fao.org/family-farming-2014/home/what-is-family-farming/pt/>. Acesso em: abril 2014.

GRASSI NETO, Roberto. Segurança alimentar: da produção agrária à proteção do consumidor. São Paulo: Saraiva, 2013.

INSTITUTO BRASILEIRO DE GEOGRAFIA E ESTATÍSTICA. Censo Agropecuário 2006: agricultura familiar - primeiros resultados. Disponível em: 
<http://biblioteca.ibge.gov.br/visualizacao/periodicos/50/agro_2006_agricultura_familiar.pdf $>$. Acesso em 25 set. 2016.

MALUF, Renato Sérgio Jamil. Segurança alimentar e nutricional. Petrópolis: Vozes, 2007.

; REIS, Márcio Carneiro dos. Conceitos e princípios de segurança alimentar e nutricional. In: ROCHA, Cecília; BURLANDY, Luciene; MAGALHÃ̃ES, Rosana (Orgs.). Segurança alimentar e nutricional: perspectivas, aprendizados e desafios para as políticas públicas. Rio de Janeiro: Editora FIOCRUZ, 2013.

MANIGLIA, Elisabete. As interfaces do direito agrário e dos direitos humanos e a segurança alimentar. São Paulo: Cultura Acadêmica, 2009.

SANTOS, Eric Gumes Lobo dos; COUTO, Vitor de Athayde; ROCHA, Alynson dos Santos. A multifuncionalidade e a questão agrária no Brasil: uma análise da agricultura familiar como geradora das novas funções da agricultura. Disponível em:

<http://www.sober.org.br/palestra/2/1031.pdf> Acesso em 26 set. 2016.

SANTOS, Janaína Silva dos. Problemáticas da segurança alimentar e nutricional no Brasil e o papel da pequena propriedade rural na efetivação de políticas públicas contra a fome e na proteção do meio ambiente. 2012. 102f. Trabalho de Conclusão de Curso (Bacharel em Direito) - Faculdade de Ciências Humanas e Sociais, Universidade Estadual Paulista "Julio de Mesquita Filho", Franca, 2012.

SIQUEIRA, Dirceu Pereira. Teoria geral do direito à alimentação: cultura, cidadania e legitimação. Birigui: Boreal Editora, 2015.

TRENTINI, Flávia. Agricultura multifuncional: inserção jurídica do agroturismo. In: SEMINÁRIO NACIONAL DE DIREITO AGRÁRIO, 10.; ENCONTRO NACIONAL DE PROFESSORES DE DIREITO AGRÁRIO, 1., 2002, Brasília, DF. Anais.... Brasília, DF: ABDA, 2002. Disponível em: 〈http://www.abda.com.br/texto/FlaviaTrentini2.pdf>. Acesso em: set. 2016.

VALENTE, Flávio Luiz Schieck (Org.). Direito humano à alimentação: desafios e conquistas. São Paulo: Cortez, 2002.

. O direito à alimentação. In: LIMA JÚNIOR, Jayme Benvenuto; ZETTERSTROM, Lena. Extrema pobreza no Brasil: a situação do direito à alimentação e moradia adequada. Rio Grande do Sul: Loyola, 2002a. p. 51-108.

WOLFF, Ana Carolina. Direito à soberania alimentar e ao patrimônio cultural: perspectivas para uma alimentação identitária. 2015. 135f. Dissertação (Mestrado em Direito) - Faculdade de Ciências Humanas e Sociais, Universidade Estadual Paulista "Júlio de Mesquita Filho”, Franca, 2015. 